\title{
Application of modern geodetic tools in the operation of railway reconstructions
}

\author{
Yuriy Ten ${ }^{1}$, Rustam Oymatov ${ }^{2 *}$, Kholmurod Khayitov ${ }^{2}$, Guzal Saydalieva ${ }^{2}$, Ulugbek \\ Nulloev $^{2}$ and Izzatillo Nematov ${ }^{3}$ \\ ${ }^{1}$ SUE “UZGASHKLITI”, 100096, Katartal str., 38, Tashkent, Uzbekistan \\ ${ }^{2}$ TIIAME, 100000, Koriy Niyozy str., 39, Tashkent, Uzbekistan \\ ${ }^{3}$ Karshi branch of TIIAME, 19, Khanabad str., Karshi city, Uzbekistan.
}

\begin{abstract}
This research considers the survey of the circular curve of the operating railway using an electronic total station, which determines the coordinates of points on the curve and calculates the coordinates of the main points of the circular curve. The goal is obtaining information with sufficient accuracy about the spatial position of the parameters of the railway plan, i.e. the device of the railway plan: turning angles, radiuses, lengths of straight lines and curves. Recommendations for determining the elements necessary to locate the main points of curves and their coordinates are considered. The advantage of this method is the simplicity of calculation, which allows the compiled program and high efficiency of determining the main points of curves using a modern geodetic device-the electronic total station Trimble VX (USA).
\end{abstract}

Keywords: Curve, parameter, program, calculation, angle, total station.

\section{Introduction}

Currently, in the tasks of inventory of Railways and railway stations, it is possible to create automated databases, which will be based on digital and electronic plans of stations and crossings within the railway right-of-way. For these purposes, modern measurement tools are widely used in the form of electronic total stations, GNSS, laser scanners, unmanned aerial vehicles (UAVs) and aerospace survey methods. They allow you to get the necessary information about the area and objects most objectively, accurately and quickly [9-11].

On Railways, to ensure the safety of train traffic, the technical operation rules provide for constant monitoring of the condition of the track, track devices and structures. The control can be performed using track measuring devices, as well as by conducting special geodetic measurements [4-8].

One of the most important stages of shooting with electronic total station of operated Railways is the shooting of its curved sections. It is performed for the purpose of drawing a curve on the plan, determining the elements of the curve, as well as the values of straightening (straightening) the path to give it a calculated shape [1-3, 13-14].

\footnotetext{
* Corresponding author: zohid3095@gmail.com
} 


\section{Methodology}

The correct position of the track in the plan ensures smooth running of trains and the least impact of rolling stock on the track. Therefore, periodically check the curves of the path, and according to the results of the check, they are straightened (straightening). Survey of the planned position of the curve geodesic method is usually performed in three Methods:

1. measuring deflection arrows with a chord length of $10-20 \mathrm{~m}$;

2. using theodolite, method of I. V. Gonikberg;

3. sighting the curve using an electronic total station [10-12].

We will consider the third method - shooting a circular curve of railway tracks using an electronic total station Trimble VX (USA) polar method from the point of the total station with the direct determination of the coordinates of its points on twenty - or ten-meter segments. At each point of the railway track to be removed, a rack with a retroreflector is installed and the distance to this point, as well as the horizontal and vertical angles to it are measured and recorded. These measurements are used to determine the planned and altitude position of these points relative to the total station (Fig.1).

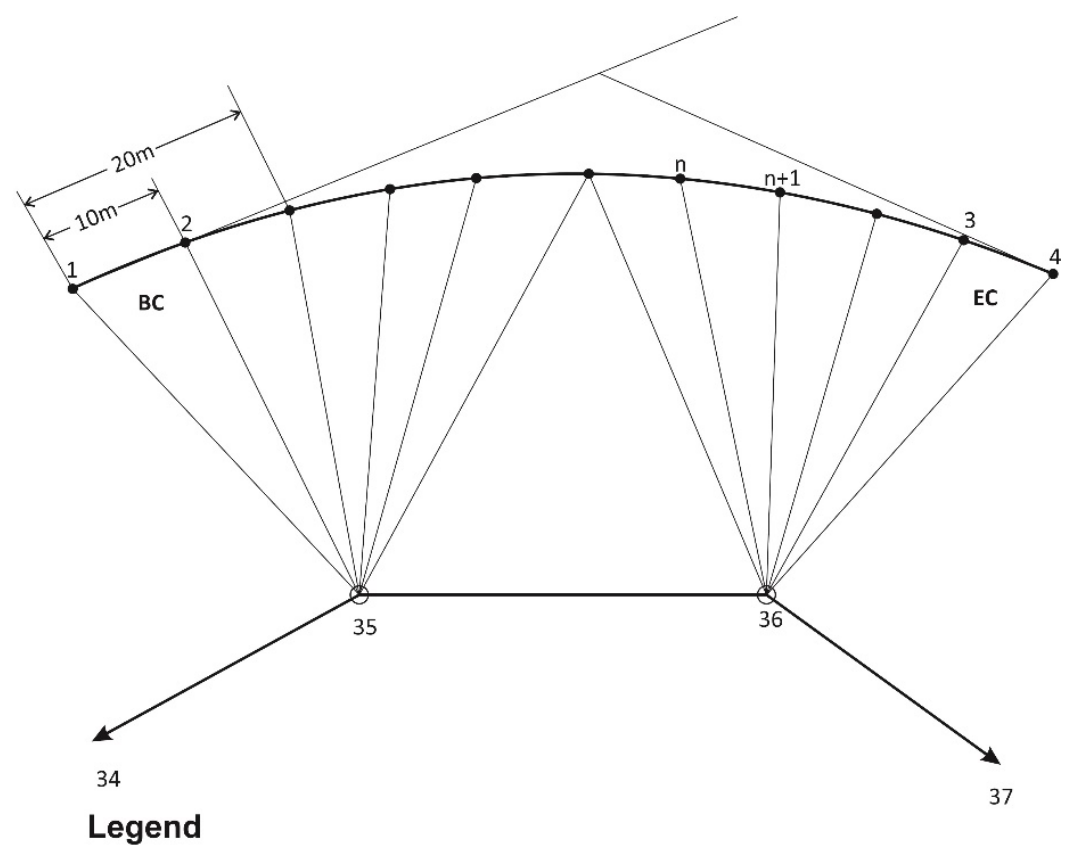

\section{o 35 The point the traverse and its number \\ $1,2,3 \ldots n, n+1$ No. of points defined by the curve of railway tracks}

Fig.1. Sighting the railway using the polar method

Staying points of the total station must be determined from the theodolite course of accuracy 1: 3000 to obtain survey results in a single coordinate system and heights. The accuracy of this method of sighting any point of the curve is no more than $5 \mathrm{~mm}$, the average square error of measuring the angle and length of the line is respectively: the angle - 1", line - $\pm(2 \mathrm{~mm}+2 \mathrm{~mm} / \mathrm{km})$ electronic total station Trimble VX (USA), which makes it easy to bring the shifted curves to design data [10]. 
Performing survey work with the installation of an electronic total station outside the railway track not only increases labour productivity due to the need to remove the device and clear the way for passing trains with its subsequent installation and performance of work on orientation to the initial direction, but also, most significantly, significantly increases the safety of geodetic activities [11-13].

The coordinates of points are used to determine the elements of the radius, rotation angle, and main points of the circular curve, as well as the coordinates of the circular curve (fig.2).

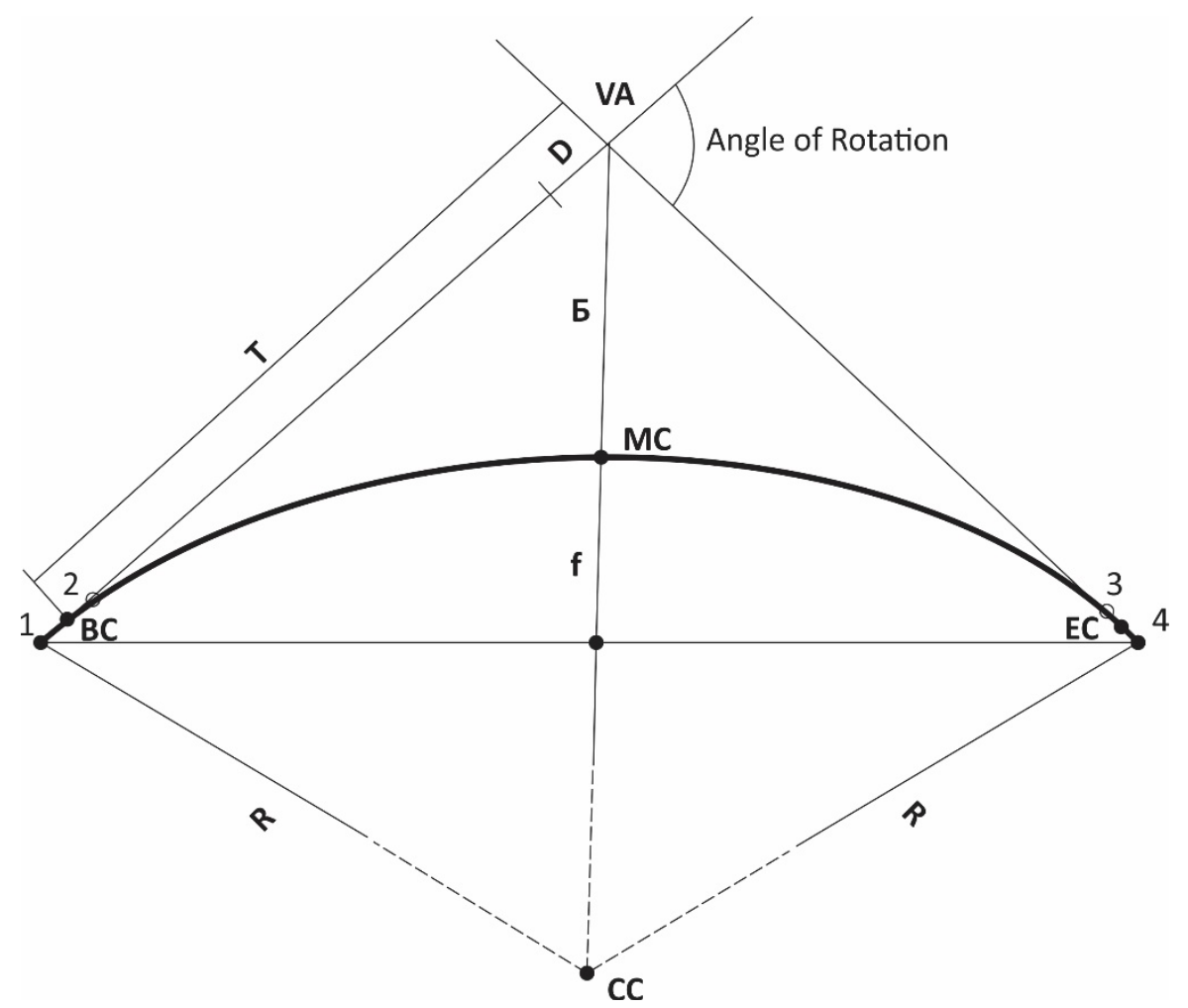

Fig. 2. Scheme of the positions of the main points of curves

Descriptions of the scheme:

- VA - vertex angle of the rotation;

- 1, 2, 3, 4-measuring points;

- $\mathrm{BC}$ - beginning of the curve;

- $\quad \mathrm{EC}$ - end of the curve;

- $\mathrm{MK}$ - middle of the curve;

- $\quad \mathrm{CC}-$ center of the curve;

- $\mathrm{f}$ - deflection;

- $\quad \mathrm{R}$ - radius of the circular curve;

- $\mathrm{B}$ - bisector;

- $\quad \mathrm{T}$ - tangent;

- D-domer;

- Line 1-4-string. 
The calculation is performed for the case of an asymmetric location of the midpoint of the curve described [4].

The coordinates of the vertex of the rotation angle are calculated using the following formulas:

$$
\begin{aligned}
& x_{V A}=\frac{\left(x_{2}-x_{1}\right) *\left[x_{3} *\left(y_{4}-y_{3}\right)-y_{3} *\left(x_{4}-x_{3}\right)\right]-\left(x_{4}-x_{3}\right) *\left[\left(x_{1} *\left(y_{2}-y_{1}\right)-y_{1} *\left(x_{2}-x_{1}\right)\right]\right.}{\left(x_{2}-x_{1}\right) *\left(y_{4}-y_{3}\right)-\left(x_{4}-x_{3}\right) *\left(y_{2}-y_{1}\right)} \\
& y_{V A}=\frac{\left(y_{2}-y_{1}\right) *\left[x_{3} *\left(y_{4}-y_{3}\right)-y_{3} *\left(x_{4}-x_{3}\right)\right]-\left(y_{4}-y_{3}\right) *\left[\left(x_{1} *\left(y_{2}-y_{1}\right)-y_{1} *\left(x_{2}-x_{1}\right)\right]\right.}{\left(x_{2}-x_{1}\right) *\left(y_{4}-y_{3}\right)-\left(x_{4}-x_{3}\right) *\left(y_{2}-y_{1}\right)}
\end{aligned}
$$

where: $x_{V A}, y_{V A}-$ coordinates of the vertex of the rotation angle;

$x_{1}, y_{1}-x_{4}, y_{4}-$ coordinates of the measured curve points.

The angle of rotation of the curve $\alpha$ is calculated using the formulas:

$$
\begin{aligned}
A_{2-1} & =\operatorname{arctg} \frac{y_{1}-y_{2}}{x_{1}-x_{2}} \\
A_{3-4} & =\operatorname{arctg} \frac{y_{4}-y_{3}}{x_{4}-x_{3}} \\
\alpha & =A_{3-4}-A_{2-1}
\end{aligned}
$$

The distances from the angle of rotation to points on straight sections of the path located near the beginning and end of curves are calculated using the following formulas:

$$
\begin{aligned}
& d_{(2-V A)}=\sqrt{\left(x_{V A}-x_{2}\right)^{2}+\left(y_{V A}-y_{2}\right)^{2}}, \\
& d_{(V A-3)}=\sqrt{\left(x_{3}-x_{V A}\right)^{2}+\left(y_{3}-y_{V A}\right)^{2}} .
\end{aligned}
$$

To determine the deflection arrow $\mathrm{f}$, the distances between measurement points $1-2$ and $3-4$ are analysed (fig.3). The triangle with the largest distance is taken into consideration. The deflection arrow is calculated using the area of the triangle.

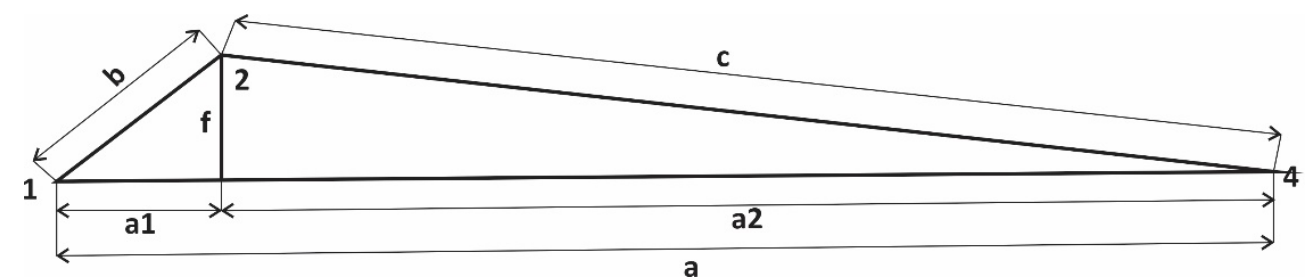

Fig. 3. Scheme for determining $f$ and $R$

The lengths of the sides of the triangle are determined:

$$
\begin{gathered}
d_{(1-2)}=b=\sqrt{\left(x_{2}-x_{1}\right)^{2}+\left(y_{2}-\mathrm{y}_{1}\right)^{2}}, \\
d_{(2-4)}=c=\sqrt{\left(x_{3}-x_{2}\right)^{2}+\left(y_{3}-\mathrm{y}_{2}\right)^{2}}, \\
d_{(1-4)}=a=\sqrt{\left(x_{3}-x_{1}\right)^{2}+\left(y_{3}-\mathrm{y}_{1}\right)^{2}} .
\end{gathered}
$$

The area of the triangle is calculated:

$$
S=\sqrt{p(p-a)(p-b)(p-c)},
$$


where: $p=\frac{a+b+c}{2}$.

The value of the deflection boom $\mathrm{f}$ is determined by the formula:

$$
f=\frac{2 S}{a}
$$

The value of the radius of the curve is calculated through the deflection arrow $f$ when the midpoint is not symmetrical according to the formula:

$$
R=\frac{a_{1} a_{2}}{2 f}
$$

where: $a_{1}$ and $a_{2}$-distances from the extreme points to the base of the deflection boom.

According to the value of the rotation angle $\alpha$, the radius of the curve $\mathrm{R}$, circular and transition curves are calculated [6]:

- tangent (T) according to the formula $-T=R \operatorname{tg} \frac{\alpha}{2}$;

- length of curve $-K=R \alpha$,

where: the angle $\alpha$ in radian indicator;

- domer $-D=2 T-K$;

- bisector $-\mathrm{B}=\mathrm{R}(1 /(\cos \alpha / 2)-1)$.

The coordinates of the main points of the curve are determined using the following algorithms:

- Coordinates of the beginning point of the curve $\mathrm{BC}$ are calculated from the point VA by the directional angle of the line 2-1 and the length of the tangent $T$;

- The coordinates of the point at the end of the EC curve are calculated from the point VA by the directional angle of the line 3-4 and the length of the tangent T;

- Coordinates of the centre point of the curve $\mathrm{CC}$ is defined as the intersection point of two circles with radius $\mathrm{R}$ and centers at points $\mathrm{BC}$ and $\mathrm{EC}$;

- The coordinates of the point midpoint of the MC curve are calculated from the point $\mathrm{CC}$ by the directional angle of the CC-VA line and the length of the radius of the curve R.

Based on the above formulas, the program "Calculation of railway curve parameters" in the Delphi 7 integrated environment has been compiled [5].

\section{Results}

To perform calculations using the program "calculation of parameters of the circular curve of the railway", information need to be prepared in the form of a text file. The data separator in the file is a semicolon (;). The sample string line looks like below.

m637;67674,05;16444,84;426,46;

where: $\mathrm{m} 637$ - name (number) of the point;

67674,05 - the X coordinate;

16444,84 - the Y coordinate;

426,46 - point mark (may be omitted).

To calculate the curve parameters, select points near the beginning (BC) and end (EC) of the curve. For example: according to the scheme fig.4. there are points 1, 2 and 3, 4. In this sequence they are entered for calculation. 


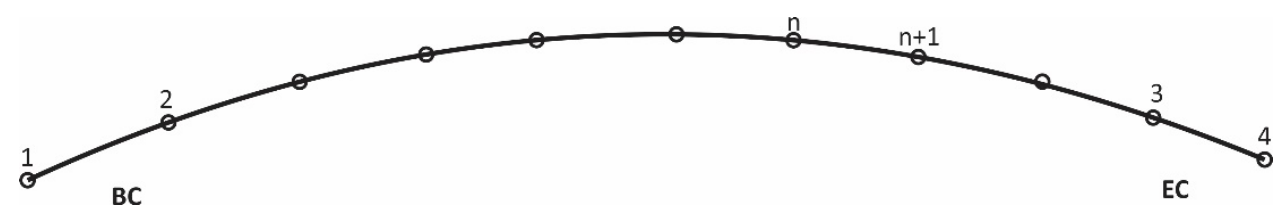

Fig. 4. Scheme of the shooting curve

Applying program in the calculation is performed in the following order:

1. Run the program (see fig.5);

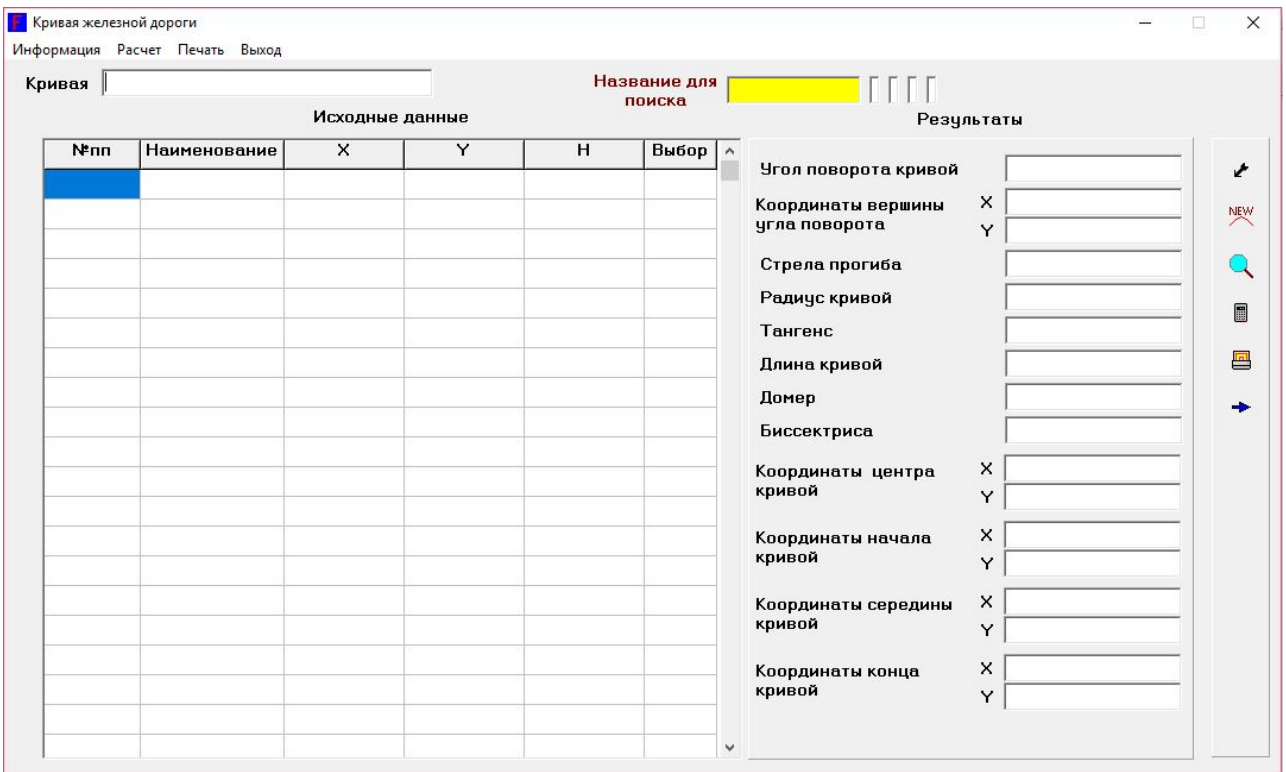

Fig. 5. The interface of the program

2. Enter information (Главное меню - Информация - Чтение данных) or select on the right side of the panel. Information can be entered directly into the table on the screen (for each item: name, coordinates $\mathrm{X}$ and $\mathrm{Y}$ );

3. Type the name of the item in the "Название для поиска" window and select $\square$ in the panel. The required item will be selected from the table, and it will be assigned the sequence number required for the calculation. To the right of the "Название для поиска" window, there is an indicator that indicates how many points are selected;

4. Select (Главное меню - Расчет) or 粼 on the panel calculate the curve;

5. After analyzing the received data, we print the results (Главное меню - Печать) or on the panel. The curve name is formed from the names of points in the Curve window (fig.6 and tables 1-3). This name can be changed at will;

6. To calculate a new curve, select (Главное меню - Информация - Новая кривая) or ${ }^{\mathrm{N} W \mathrm{~W}}$ on the panel. Then follow the steps starting from point No 2 or No 3.

7. Exit from the program is performed (Главное меню - Выход) or $\Rightarrow$ on the panel. 


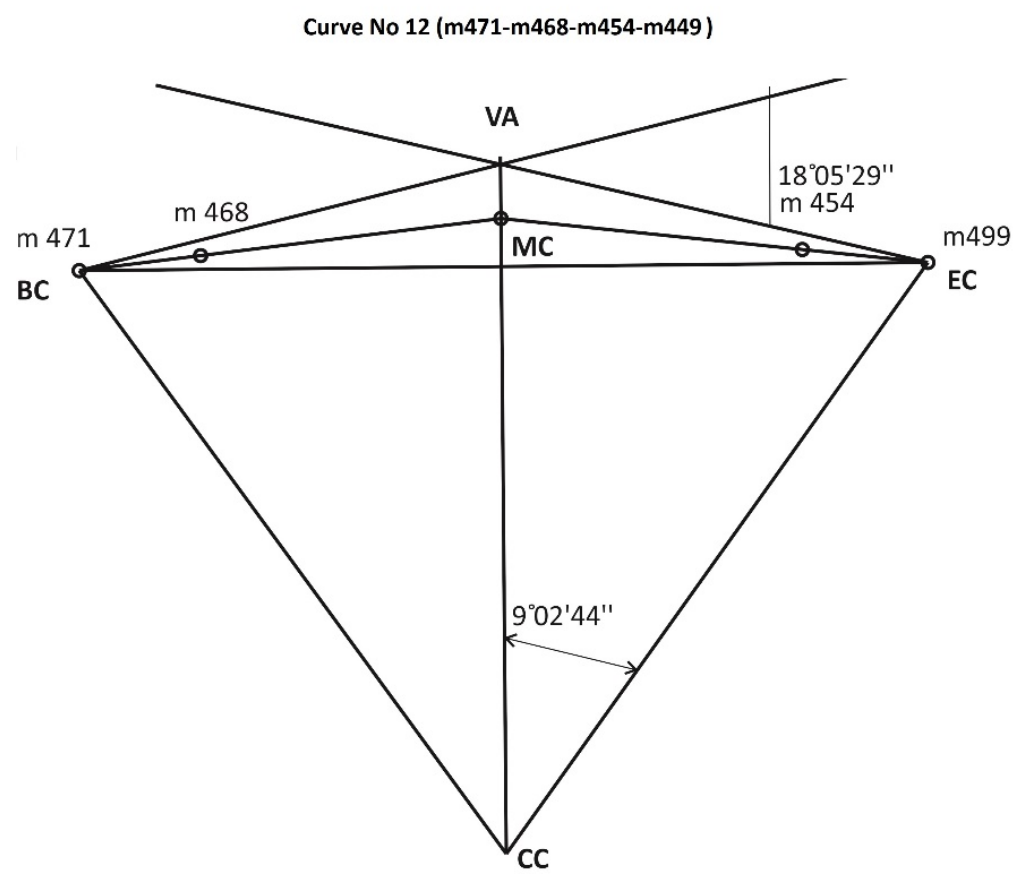

Fig.6. Calculation of circular curves (example)

Table 1. Entered data

\begin{tabular}{|c|c|c|}
\hline Name or number of points & $\mathbf{X}$ & $\mathbf{Y}$ \\
\hline $\mathrm{m} 468$ & 67703.92 & 16439.79 \\
\hline $\mathrm{m} 471$ & 67696.77 & 16439.16 \\
\hline $\mathrm{m} 454$ & 67733.44 & 16437.94 \\
\hline $\mathrm{m} 449$ & 67744.35 & 16435.41 \\
\hline
\end{tabular}

Table 2. Result of calculation

\begin{tabular}{|l|l|}
\hline Rotation angle of way & $18^{0} 05^{\prime 2} 9^{\prime \prime}$ \\
\hline Radius of the circular curve & 122.57 \\
\hline Tangent, T (m) & 19.51 \\
\hline The length of the curve K (m) & 38.70 \\
\hline Domer D (m) & 0.32 \\
\hline Bisector of curve B (m) & 1.54 \\
\hline Chord length (m) & 40.67 \\
\hline Deflection arrow f (m) & 1.34 \\
\hline
\end{tabular}

Table 3. Coordinates of the main points of the circular curve

\begin{tabular}{|l|c|c|}
\hline \multicolumn{1}{|c|}{ Name of points } & X & Y \\
\hline Vertex of the rotation angle, VA & 67719.53 & 16441.17 \\
\hline Center of the curve, CC & 67710.85 & 16317.36 \\
\hline Beginning of the curve, BC & 67700.09 & 16439.45 \\
\hline Middle of the curve, MC & 67719.42 & 16439.63 \\
\hline End of the curve, EC & 67738.54 & 16436.76 \\
\hline
\end{tabular}




\section{Discussion}

Obtaining information with sufficient accuracy about the spatial positions of the parameters of the railway plan, i.e. the device of the railway plan: turning angles, radiuses, lengths of straight lines and curves. The advantage of above mentioned method is the simplicity of calculation, which allows the compiled program and high efficiency of determining the main points of curves using a modern geodetic device - the electronic total station.

\section{References}

1. KMK 3.06.05-98, Railway, road and hydraulic tunnels. Metros. Production and acceptance of works (1998);

2. ShNK 1.02.07-15, Engineering and technical surveys for construction. Fundamentals (2015)

3. V. I. Poletaev, E. G. Tolstov. Sighting railway curves, Saint-Petersburg, p. 37 (2011)

4. A. Khomonenko, V. Hoffman, E. Meshcheryakov, V. Nikiforov, Delphi 7, SaintPetersburg, pp. 1201 (2003).

5. V. N. Ganshin, L. S. Khrenov. Tables for splitting circular and transition curves. 4th ed., Kiev, p. 432 (1974)

6. A. Inamov, J. Lapasov and S. Hikmatullaev. Engineering surveying, Tashkent, p. 200 (2017)

7. E. Nurmatov, U.Utanov. Geodesy, Tashkent, p.234 (2002)

8. Sh. Avchiev. Applied Geodesy, Tashkent, p.166 (2007)

9. T. Abdullaev, U. Islamov, U. Mukhtorov and A. Inamov. Advanced Geodesy, Tashkent, p.224 (2017)

10. W .Schofield. Engineering surveying, Oxford, p.534 (2001)

11. R. Abdiramanov, A. Ninamov, A. Dadaboeva. Internauka. 12 (46) (2018)

12. S. Tashpulatov, B. Nazarov, N. Shavkatova. Modern geodetic instruments, Tashkent, p.300 (2018)

13. H. Muborakov, S.Ahmedov. Geodesy and Cartography, Tashkent, p.304 (2002)

14. Z. Okhunov. Proctices from Geodesy, Tashkent, p.200 (2009)

15. S. Tashpulatov, U. Islamov, A. Inamov. Space geodesy, Tashkent, p.121 (2018) 